\title{
Optimization of oxygen consumption and reduction of organic matter from waste during the fermentation phase: Case of the composting platform in Lomé, Togo
}

\author{
Edem Komi Koledzi ${ }^{{ }^{\star}}$, Kwamivi Nyonuwosro Segbeaya ${ }^{1,2}$, and Nitale M'Balikine Krou ${ }^{2}$ \\ ${ }^{1}$ Laboratory of Waste Management, Treatment and Recovery (GTVD), Faculty of Sciences, University of Lomé, \\ P. O. Box 1515 Lomé-Togo. \\ ${ }^{2}$ Laboratory of Sanitation, Water Science and Environment (LASEE), Faculty of Science and Technology, \\ University of Kara, P. O. Box 404 Kara, Togo.
}

Received 2 December, 2020; Accepted 9 June, 2021

\begin{abstract}
In the context of carbon financing it is required that the rate oxygen inside the windrows exceeds $8 \%$ to avoid anaerobic decomposition. Thus, the objective of this study is to optimize oxygen consumption and reduce organic matter in the waste during the fermentation phase. Windrow turning is monitored, which includes monitoring of temperature, $\mathrm{pH}$, organic matter, humidity and certain metals.Temperature monitoring showed a gradual decrease until stabilization at room temperature, indicating the maturity of the compost. With a slight increase in all swaths, the $\mathrm{pH}$ remained alkaline. The humidity in the windrows promoted good aerobic degradation of the composted waste. The organic matter in these windrows has decreased to values that agree with standards. The present study has demonstrated the importance and influence of the oxygen content and the production of carbon dioxide on the mineralization of organic matter, especially during the fermentation phase.
\end{abstract}

Key words: Flipping, compost, oxygen and carbon dioxide levels.

\section{INTRODUCTION}

Composting is an ancestral technique, one of the most widely used ways of recovering materials from household wastes. It limits the use of landfill or incineration. Among the organic matter transformation processes, composting is particularly interesting for the transformation of organic matter, because it makes it possible to considerably reduce the mass and volume of the initial effluents, thus allowing a reduction in transport costs. It is a controlled process of degrading organic materials of plant or animal origin. During intense transformations of organic matter (OM), a transfer of pollution to the atmosphere is possible depending on the substrates put to compost and the methods of composting (Tchegueni et al., 2012). Faced with this observation, ensuring the environmental impact of composting, in particular for organic matter in household waste is essential. However, during this process a significant amount of water and dry matter is lost (about $50 \%$ of the initial masses), mainly in gaseous

*Corresponding author. E-mail: edemledzi@yahoo.fr. Tel: 0022890198535.

Author(s) agree that this article remain permanently open access under the terms of the Creative Commons Attribution License 4.0 International License 
form. This aerobic biological treatment allows a return to the soil of stabilized organic matter. In this process, the degradation of the substrates is marked by the decrease in organic matter, also indicating that the compost obtained is mineralized (Tchegueni et al., 2012). When aeration is done well, we obtain a mature compost after three months. In fact, the degree of maturity of a compost is the stage at which the compost no longer has a negative effect on plants (Koledzi, 2011). Composting also helps to reduce the emission of methane, which is a Greenhouse Gas (GHG) responsible for global warming (Sánchez et al., 2015). To reduce the risk of methane emissions, this aerobic process requires large amounts of oxygen, especially at the initial stage. Aeration is the source of oxygen, and thus is found to be an essential factor for aerobic composting. When the oxygen supply is not sufficient, the growth of aerobic microorganisms is limited, which slows down decomposition (Bokobana et al., 2017). Thus, good aeration is essential for efficient composting. This can be achieved if the physical quality of the materials (particle size and water content), the size of the pile and the ventilation are controlled and if the waste mixture is frequently turned. The fermentation phase requires controlling humidity, temperature and air supply. Oxygen is supplied in various ways. The turning of the swath, the air blowing (mechanical ventilation system using fans or aeration pipes inside the windrow) and the natural circulation of air between the particles of material first are methods commonly used to ensure the supply of air. In fact, aeration provides the oxygen necessary for good biological degradation of the substrates (Turan and Ergun, 2008). According to the same study, oxygen consumption is generally high during the fermentation phase and decreases as the composting process progresses. Some authors have shown that the presence of oxygen at a minimum threshold of around 5 $\%$ oxygen is essential for the successful completion of composting (Puyuelo et al., 2010). This oxygen is also consumed by microorganisms during their activity and on the other hand by oxidation reactions. For others still, the oxygen level is directly related to the percentage of gaps (porosity) in the material to be composted, to the particle size of the particles present and to the humidity of the compost (Mustin, 1987). This is because the higher the porosity, the easier the air circulation. Humidity acts in the opposite direction. Decomposition of organic matter is inhibited when the water content drops below $20 \%$. If it exceeds $70 \%$, the water begins to fill the waste spaces and prevents oxygen exchange, thus causing conditions favorable to anaerobiosis (Toundou, 2018). Optimal composting is obtained for values of 30 to $36 \%$ porosity in the mass (Mustin, 1987). In addition, if the grain size is too fine, it causes "suffocation" of the windrow, if it is too coarse it can be synonymous with drying out due to the significant air circulation; grinding of the waste is therefore necessary to obtain a favorable particle size and a good mixture of the substrates. According to the same study, the oxygen level changes over time: aerobic microorganisms use oxygen and release $\mathrm{CO}_{2}$, which tends to deplete the environment in $\mathrm{O}_{2}$, but the air circulation in the heap of compost renews the atmosphere and enriches the environment with $\mathrm{O}_{2}$. An intervention (turning over) may then be necessary to restore the aerobic conditions of the composting. Several indicators are used to characterize the aerobic evolution of the composting process. However, monitoring the level of oxygen $\left(\mathrm{O}_{2}\right)$ seems to be a scientifically more reliable indicator than monitoring the level of $\mathrm{CO}_{2}$ to characterize the aerobic evolution of a compost heap. Insofar as a minimum level of oxygen is necessary for good aerobic degradation and that composting platforms must limit emissions of carbon dioxide, which is a GHG, it is urgent to find alternatives to optimize oxygen consumption and the production of carbon dioxide.

In Togo, the composting platform of the company ENPRO has been involved in the carbon credit process for more than six years, in 2013. In fact, in the context of carbon financing where the platform is involved, the oxygen level inside the windrows must exceed $8 \%$ to avoid anaerobic decomposition, a value taken above that indicated in the literature to guarantee optimal aeration. Thus, the objective of this study is to optimize the oxygen consumption and the production of carbon dioxide in windrows. To do this, windrow turning is monitored, which includes monitoring of the evolution of oxygen $\left(\mathrm{O}_{2}\right)$, carbon dioxide $\left(\mathrm{CO}_{2}\right)$, organic matter $(\mathrm{OM})$, humidity and certain metals.

\section{MATERIALS AND METHODS}

\section{Material}

The raw materials used in this study are the biodegradable fractions of urban waste obtained after sorting unwanted materials on the site of the NGO "ENPRO" Clean Natural Ecosystem in Lomé. Figure 1 shows the waste collected and dumped on the composting site.

Five compost heaps (windrows) were made after sorting the waste from various pre-collection structures in the city of Lomé; these are windrows $\mathrm{A}, \mathrm{B}, \mathrm{C}, \mathrm{D}$, and $\mathrm{E}$.

\section{Methods}

\section{Composting methods}

In this study, composting in heaps or windrow is adopted. In fact, the waste dumped on the site is sorted and free of nonbiodegradable materials on a sorting table (Figure 2). In Lomé, the rate of sand in the waste is between $35-44 \%$ (Koledzi, 2011) $^{2}$. Thus, a mesh of $10 \mathrm{~mm}$ on the table reduces the proportion of sand.

To have the piles or windrows on the site, the putrescible or compostable waste obtained after sorting is layered (Figure 3) and gradually watered with a quantity of water proportional to the humidity of this waste. To speed up the composting process, a few kilograms of already decaying waste from an old pile launched some time ago are incorporated into the new waste during the pileup. According to a specific method, the piles are turned to facilitate 

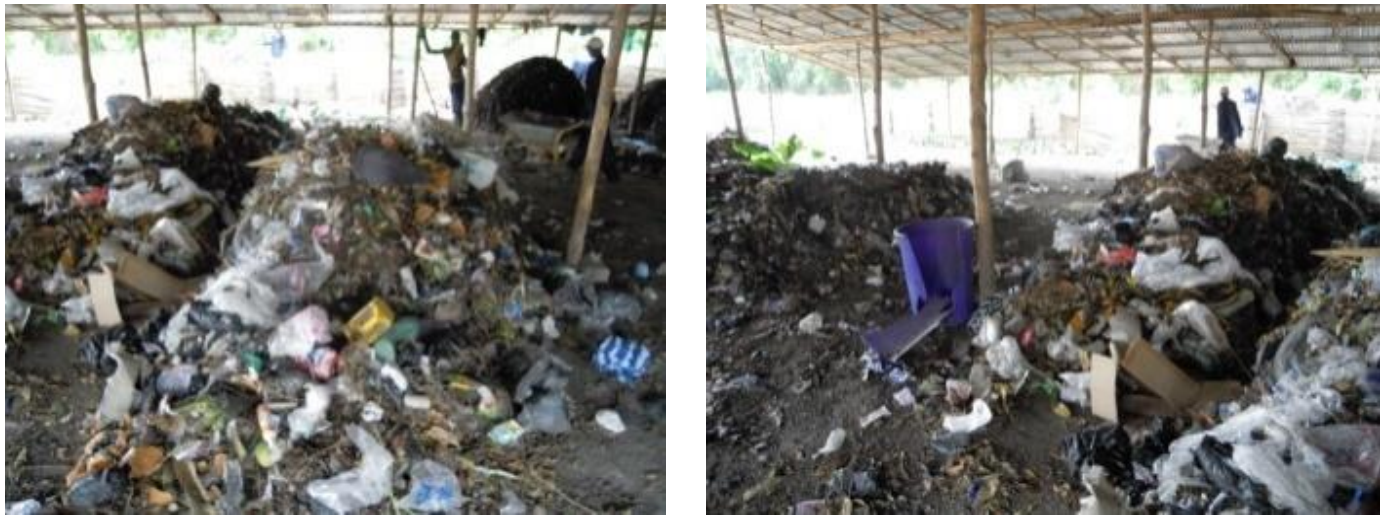

Figure 1. Waste collected and dumped on the composting site.
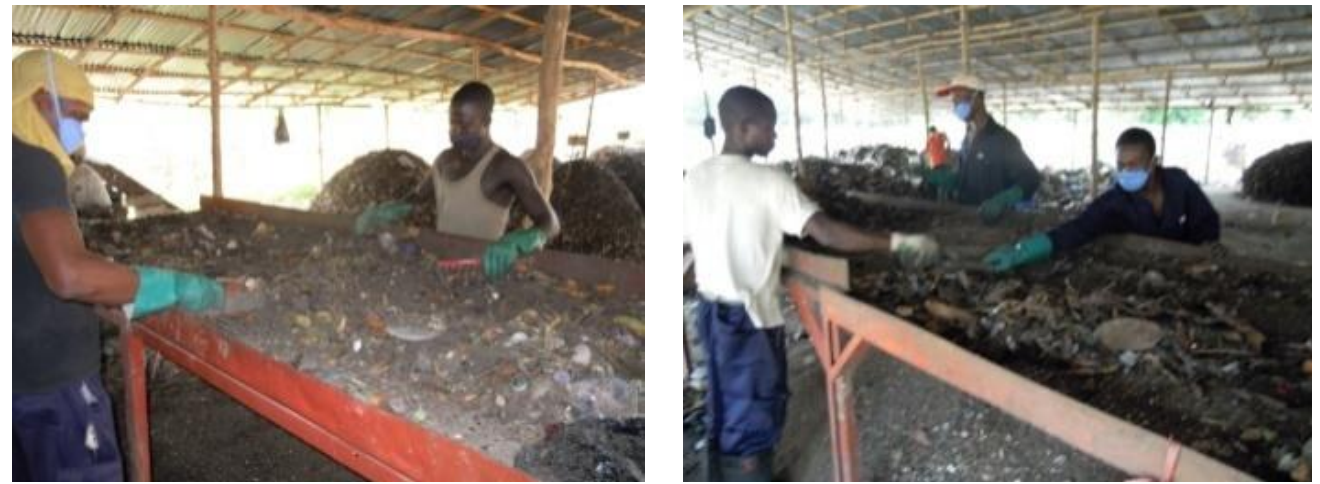

Figure 2. Sorting tables.
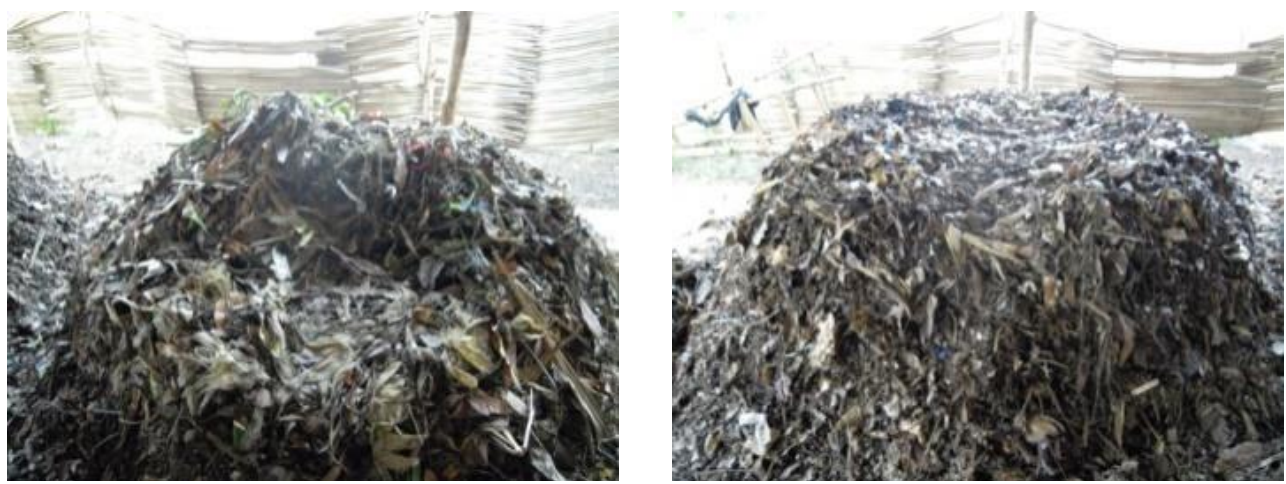

Figure 3. Windrows in preparation.

the supply of oxygen in order to avoid anaerobic transformation which can lead to the formation of foul-smelling gases and carbon dioxide (Figure 3 ). Windrows $A$ and $B$ are turned weekly. For $\mathrm{C}$ and $D$, we thought that by bringing the reversals together during the first two weeks when the activity is intense, we could therefore keep the oxygen level above $8 \%$. The following formula was used where we do four turnovers in the first two weeks: $3^{\text {rd }}$ day, $5^{\text {th }}$ day, $10^{\text {th }}$ day, $15^{\text {th }}$ day, $21^{\text {st }}$ day, $28^{\text {th }}$ day, $36^{\text {th }}$ day, $43^{\text {rd }}$ day, $50^{\text {th }}$ day, $57^{\text {th }}$ day and $64^{\text {th }}$ day. The composting period has been set at three months.

\section{Monitoring of the composting process}

Turning times correspond exactly to a fixed duration (every two weeks). The windrows were returned four times: two times during the fermentation phase and two times during the ripening phase to promote their homogenization.

In order to optimize oxygen consumption and the production of carbon dioxide in the windrows, windrow turning monitoring is carried out and which includes monitoring of physicochemical 

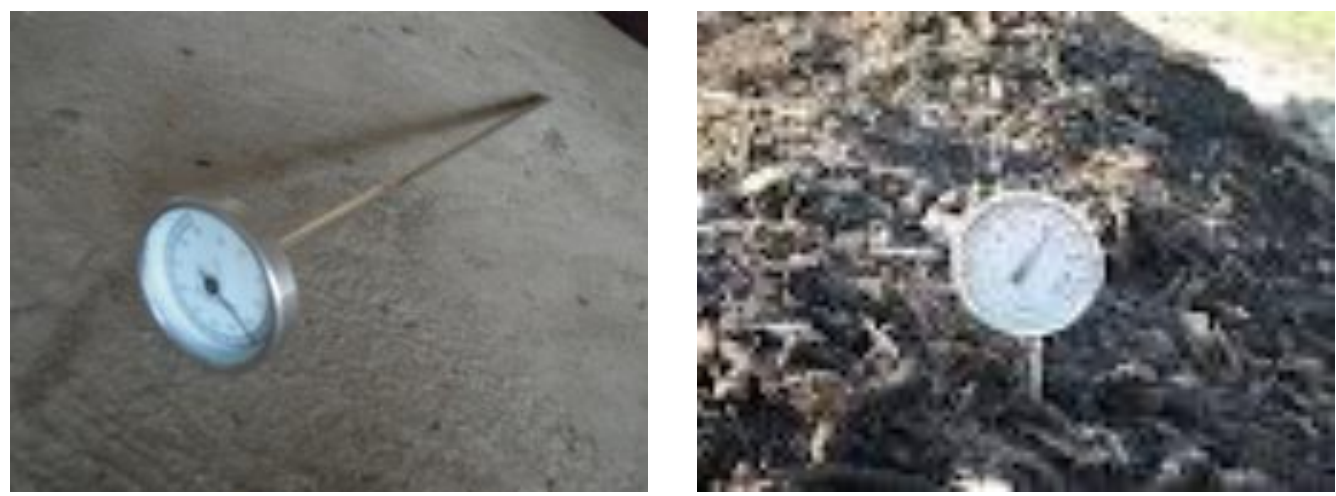

Figure 4. Thermometer used on windrows.

parameters such as temperature, hydrogen $(\mathrm{pH})$, organic matter $(\mathrm{OM})$, humidity and some metals, followed by the evolution of oxygen $\left(\mathrm{O}_{2}\right)$ and carbon dioxide $\left(\mathrm{CO}_{2}\right)$. Monitoring of $\mathrm{pH}$, organic matter (OM) and humidity is carried out weekly. The temperature was measured daily using a thermometer (Figure 4).

The $\mathrm{pH}$ was measured on an aqueous suspension using a Metrohm brand $\mathrm{pH}$ meter according to the AFNOR NF ISO 10-390 standard method (Belyaeva and Haynes, 2009).

The humidity $(\% \mathrm{H})$ was determined according to the standard Afnor NF U 44-171 method of October 1982 by formula 1:

$\% H=\frac{M_{0}-M_{1}}{M_{0}} \times 100$

$M_{0}$ : mass of the raw sample $(\mathrm{g}) ; \mathrm{M}_{1}$ : mass of the sample after passage in the oven $(\mathrm{g}) ; \% \mathrm{H}$ : percentage of humidity contained in the sample.

The total organic matter content (OM in \% of DM) was determined by the loss on ignition according to standard NF $U$ 44-160 of November 1985 by formula 2:

$\%$ MOT $=\frac{M_{1}-M_{2}}{M_{1}} \times 100$

$M_{1}$ : mass of the sample after passage in the oven $(g) ; M_{2}$ : mass of the sample after calcination (g);-\% MOT: percentage of organic matter contained in the sample

The levels of metallic trace elements were determined by flame atomic absorption spectrophotometry (Krou et al., 2019).

The $\mathrm{O}_{2}$ and $\mathrm{CO}_{2}$ were monitored using an adaptation of the Sprint $\mathrm{V}_{2}$ device which measures the combustion gases. The "Sprint $V_{2}$ gas analyzer" is a device that not only measures oxygen levels but also carbon dioxide $\left(\mathrm{CO}_{2}\right)$ and carbon monoxide (CO) levels. The Sprint $V_{2}$ is designed to detect gas leakage in industrial installations. In this work we have made an adaptation of this device. The probe is fitted with a galvanized tube. This tube is made of metal and gives resistance to heat and decomposing windrow materials, which prevent damage to the probe. The tube closed at one end is pierced with small holes around the circumference to allow gas to enter, which is trapped by a rubber stopper closing the other end through which the probe is immersed when a sufficient quantity of gas is stored. The galvanized tube of the device is immersed in the swath and the oxygen level is read when the value stabilizes. Three different measurements are made on the same pile and the average value is retained. Figure 5 shows the measurement diagram.

The oxygen level was assessed using the devices shown in
Figure 6.

\section{RESULTS}

\section{Monitoring of the composting process}

Monitoring of $\mathrm{pH}$, organic matter (OM) and humidity is carried out weekly (Table 1). Figure 7 shows the rate of reduction of organic matter as a function of time. Figures 8 and 9 show the evolution of oxygen and carbon dioxide respectively for windrows $A$ and $B$. Figures 10 and 11 show the evolution of oxygen and carbon dioxide respectively for windrows $C$ and $D$. Figure 12 shows the correlation between temperature and oxygen consumption (windrow E).

\section{Metallic trace element content}

Table 2 shows the levels of metallic trace elements in the composts.

\section{DISCUSSION}

\section{Monitoring of the composting process}

Monitoring the $\mathrm{pH}$ is an indicator of the degree of biological and biochemical decomposition (Damien, 2004). Indeed, the results show that the $\mathrm{pH}$ increases slightly over time and is between 7.4 and 8.5 for windrows. These values are in the range of values obtained for a complete and successful process of composting biodegradable waste which is 8-9 (Koledzi et al.,2019; Sundberg et al., 2004). The increase in $\mathrm{pH}$ values is believed to be due to the release of ammonium ions during the process ((Tchanaté et al., 2017); Tang et al., 2004). As for the water or moisture content $(\mathrm{H} \%)$, the optimum is between 40 and $60 \%$ for all windrows; this interval being favorable to aerobic decomposition 


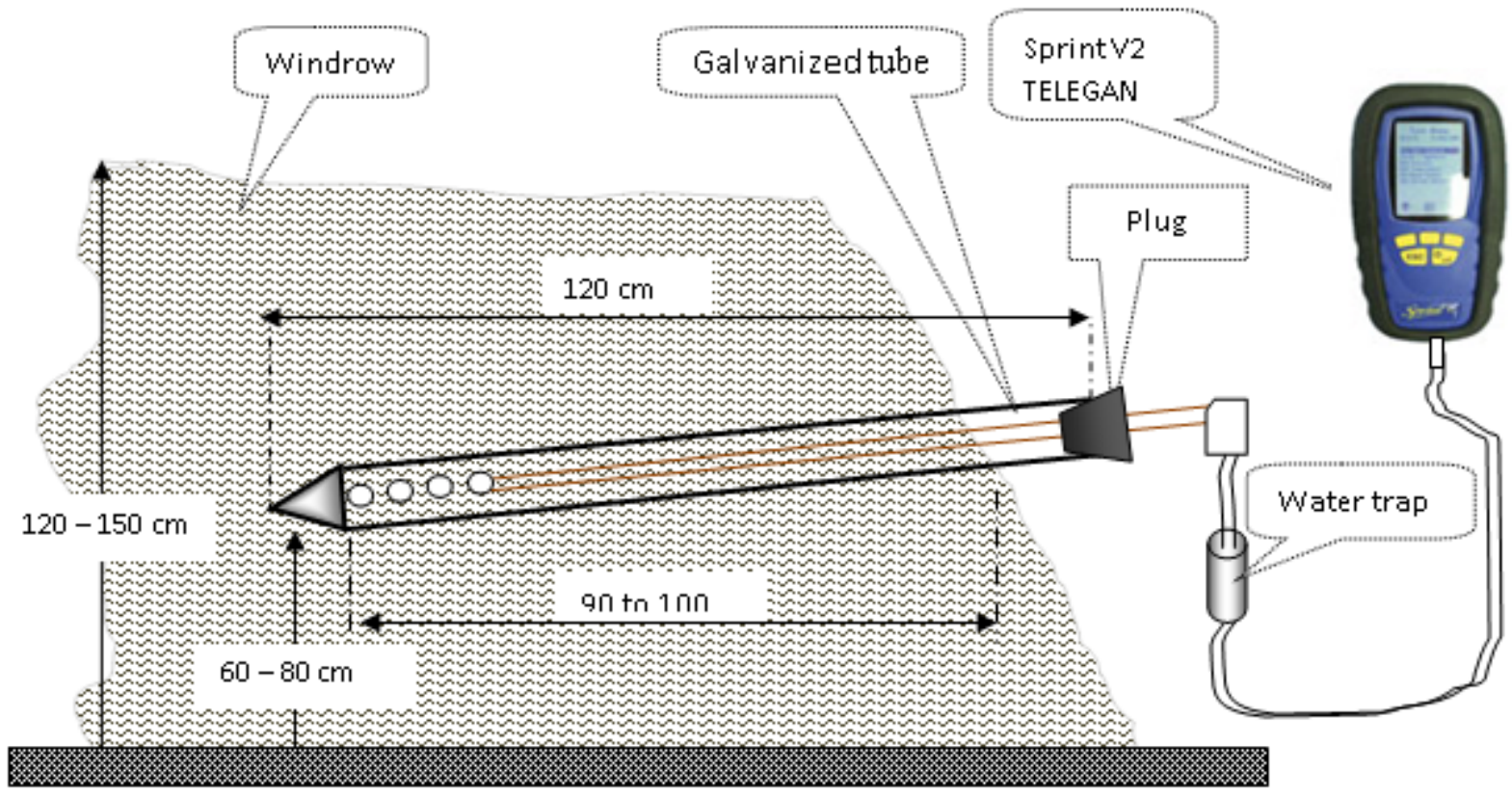

Figure 5. Measurement of $\mathrm{O}_{2}$ and $\mathrm{CO}_{2}$ in a windrow.
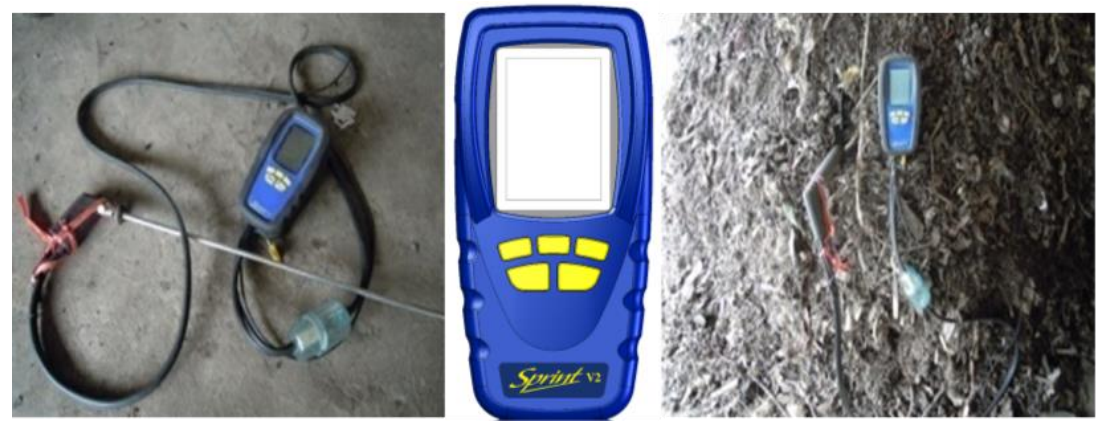

Figure 6. Device for measuring the oxygen level.

Table 1. Evolution of the parameters influencing the decomposition of organic matter.

\begin{tabular}{|c|c|c|c|c|c|c|c|c|c|c|c|c|c|c|c|c|c|c|c|c|}
\hline & & & A & & & & & B & & & & & C & & & & & D & & \\
\hline Weeks & 0 & 2 & 4 & 6 & 8 & 0 & 2 & 4 & 6 & 8 & 0 & 2 & 4 & 6 & 8 & 0 & 2 & 4 & 6 & 8 \\
\hline $\mathrm{pH}$ & 7.5 & 7.5 & 7.8 & 8.5 & 8.5 & 7.3 & 7.6 & 8 & 8 & 8.1 & 7.5 & 7.6 & 7.8 & 7.9 & 8.2 & 7.4 & 7.8 & 7.8 & 7.9 & 8.1 \\
\hline$\% \mathrm{MO}$ & 62 & 50 & 45 & 35 & 35 & 52 & 43 & 40 & 35 & 32 & 65 & 60 & 58 & 56 & 49 & 67 & 63 & 60 & 55 & 51 \\
\hline$\% \mathrm{H}$ & 45 & 50 & 37 & 49 & 51 & 55 & 52 & 44 & 47 & 39 & 43 & 60 & 55 & 40 & 43 & 62 & 51 & 54 & 44 & 40 \\
\hline $\mathrm{O}_{2}$ & & 13 & 14 & 14 & 8 & - & 11 & 14 & 4 & 8 & - & 6 & 12 & 14 & 14 & - & 6 & 12 & 14 & 16 \\
\hline $\mathrm{CO}_{2}$ & - & 3 & 6.7 & 3 & 7 & - & 1.4 & 2 & 14 & 4 & - & 9 & 3 & 2.1 & 3.8 & - & 10 & 3 & 2.1 & 3.8 \\
\hline
\end{tabular}

$\mathrm{pH}$ : potential of Hydrogen; \% OM: rate of organic matter;\% $\mathrm{H}$ : rate of humidity; $\mathrm{O}_{2}$ : oxygen; $\mathrm{CO}_{2}$ : carbon dioxide.

(Krou et al., 2019).

Regarding the organic matter content (\%OM), it decreases and after eight weeks of activity it is around $35 \%$ for windrow $A, 32 \%$ for windrow B, $49 \%$ for windrow
C and $51 \%$ for windrow D. The organic matter contents obtained for the four windrows comply with standards NFU44-051 and NFU 44-095 and indicate that the compost obtained is mature and stabilized for use as a 


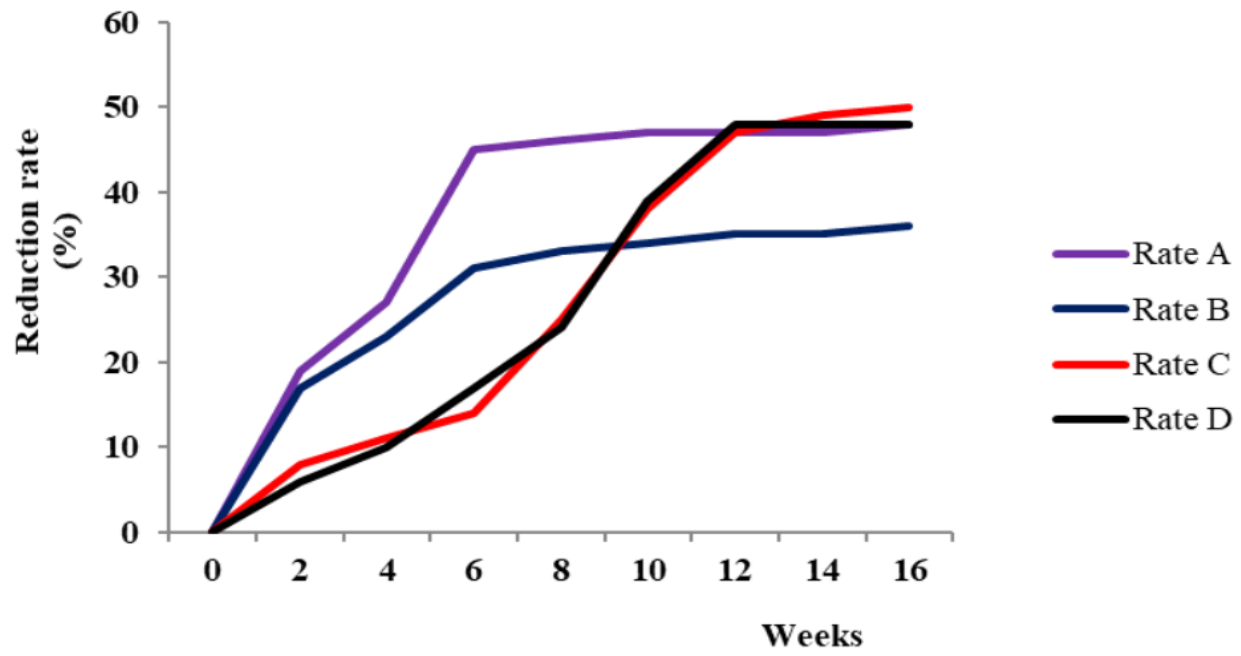

Figure 7. Organic matter reduction rate as a function of time.

Table 2. Metallic trace element content in composts.

\begin{tabular}{cccc}
\hline Elements (mg/kg MS) & Compost windrow A & Compost windrow E & NFU 44-051 \\
\hline $\mathrm{Pb}$ & 53 & 35 & 180 \\
$\mathrm{Ni}$ & 10 & 14 & 60 \\
$\mathrm{Cd}$ & 1 & $\mathrm{Nd}$ & 3 \\
$\mathrm{Cu}$ & 8 & 10 & 300 \\
$\mathrm{Zn}$ & 50 & 30 & 600 \\
\hline
\end{tabular}

soil amendment (Rafolisy, 2015).

Figure 7 shows the rate of reduction of organic matter as a function of time.

In terms of the decrease in the organic matter content during the composting process, the results show that the loss of OM after eight weeks (Figure 7 ) is $46 \%$ for swath A, $33 \%$ for B, $24 \%$ for C and $25 \%$ for swath D. After eleven weeks, only a slight reduction rate (Figure 2 ) is observed for $\mathrm{A}$ and $\mathrm{B}$, that is, 48 and $36 \%$, respectively, whereas $49 \%$ is noted for $C$ and $48 \%$ for $D$ on the same date. This result shows that the fermentation is therefore completed after seven weeks for A and B while it continues for $C$ and $D$ up to eleven weeks as shown by the abatement rates (Figure 7). This shows that composts $A$ and $B$ have entered the maturation phase after seven weeks while it is observed for composts $C$ and $D$ after 11 weeks where the mineralization of the organic matter normally becomes slower than the fermentation phase. The decomposition of organic matter is therefore slow in composts $C$ and $D$ compared to composts $\mathrm{A}$ and $\mathrm{B}$. The content at the end of maturation is on average $33 \%$ for composts $A$ and $B$ and $C$ and 35 $\%$ for $D$ relative to the dry matter. These decreases in organic matter are characteristic of the degradation of organic matter and are strongly related to oxygen consumption and carbon dioxide production. They are also linked to the mineralization of organic matter by microorganisms (Aziablé et al., 2017) with respect to the variation in humidity. In the present study, the decrease in organic matter and therefore degradation and mineralization of organic matter is influenced by the turning method. The frequency of turning in the $C$ and $D$ swaths favoring a high oxygen content and a low production of carbon dioxide slows the rate of degradation and therefore the time of the composting process. Temperature monitoring confirms this development. After each inversion, it is between $60^{\circ} \mathrm{C}$ and $70^{\circ} \mathrm{C}$ for the first seven weeks and then stabilizes between $35^{\circ} \mathrm{C}$ and $45^{\circ} \mathrm{C}$ even without inversion for the swaths $\mathrm{A}$ and $\mathrm{B}$. For the swaths $C$ and $D$, the values between $60^{\circ} \mathrm{C}$ and $70^{\circ}$ $C$ go up to 11 weeks.

Figures 8 and 9 show the evolution of oxygen and carbon dioxide respectively for windrows $A$ and $B$.

Regarding the monitoring of $\mathrm{O}_{2}$ consumption and $\mathrm{CO}_{2}$ production, Figures 8 and 9 , show that the oxygen level repeatedly drops each week compared to the carbon dioxide level until the $53^{\text {rd }}$ day of the week. composting for swath A (Figure 8) and up to day 62 for swath B (Figure 9). The activity of aerobic microorganisms is very intense. Overconsumption of oxygen is frequently 


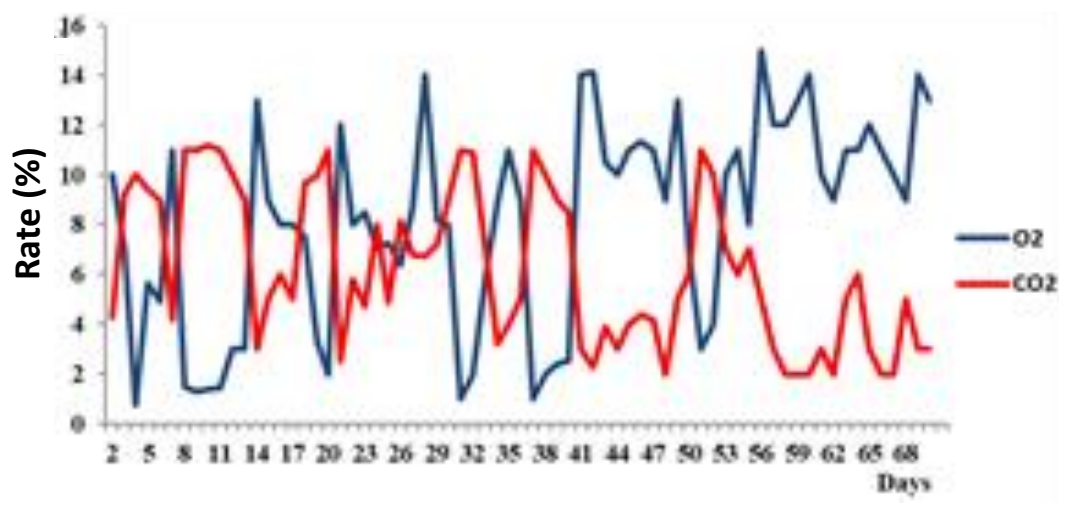

Figure 8. Evolution of $\mathrm{O}_{2}$ and $\mathrm{CO}_{2}$ in windrow $\mathrm{A}$.

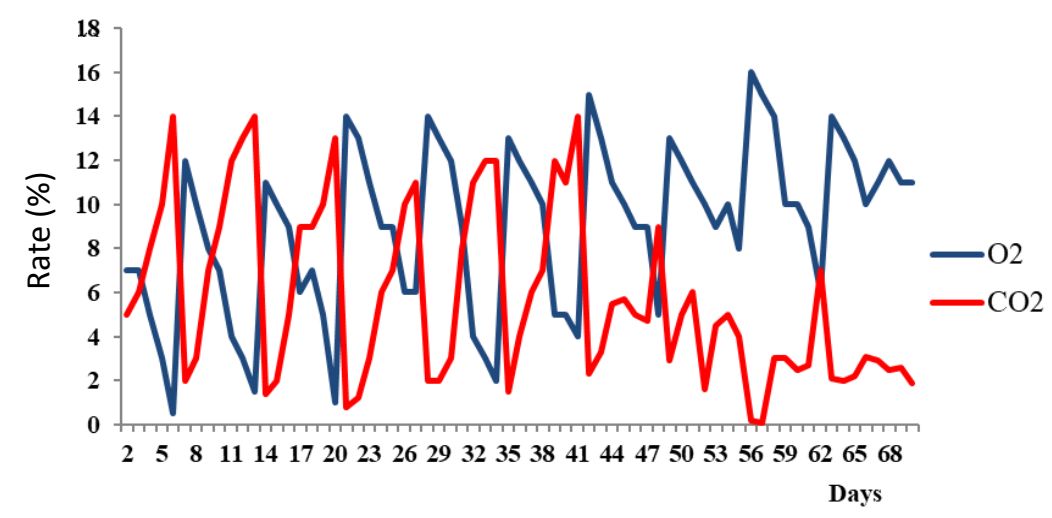

Figure 9. Evolution of $\mathrm{O}_{2}$ and $\mathrm{CO}_{2}$ in windrow $\mathrm{B}$.

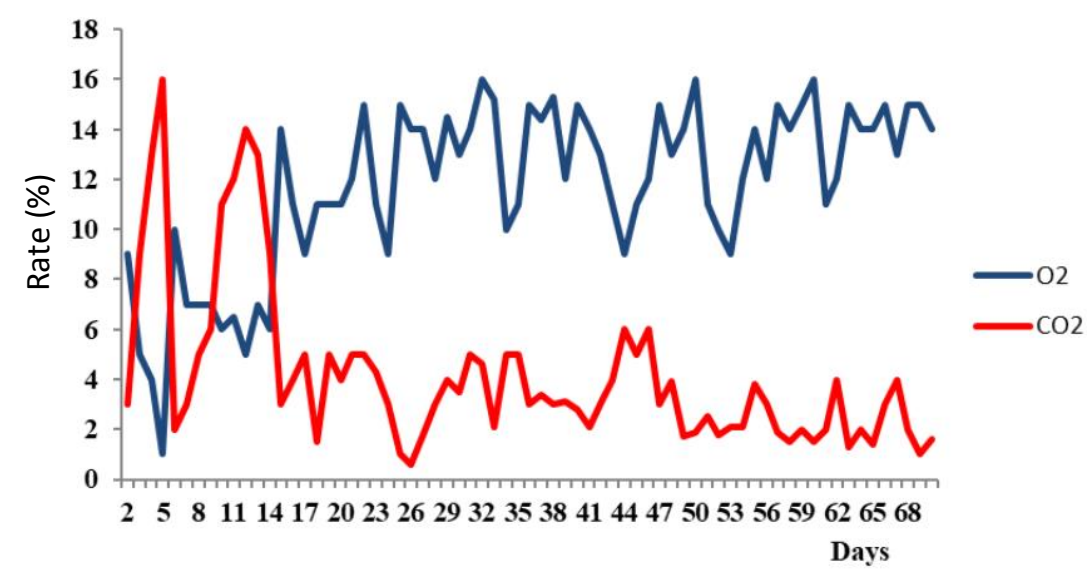

Figure 10. Evolution of $\mathrm{O}_{2}$ and $\mathrm{CO}_{2}$ in the Windrow $\mathrm{C}$.

observed in windrows $A$ and $B$ and exceeds the limit for aerobic decomposition of 5\% (Puyuelo et al., 2010). Figures 5 and 6 show that the oxygen level for windrows $\mathrm{C}$ and $\mathrm{D}$ rises above $5 \%$ from the 10th day (Figures 10 and 11 ) and above $8 \%$ from the $15^{\text {th }}$ day which is the lower rate under carbon finance. Although the activity of aerobic microorganisms is very intense, it is noted that the decomposition proceeds very slowly because the activity started inside the swath is often interrupted by turning especially during the first two weeks. This result 


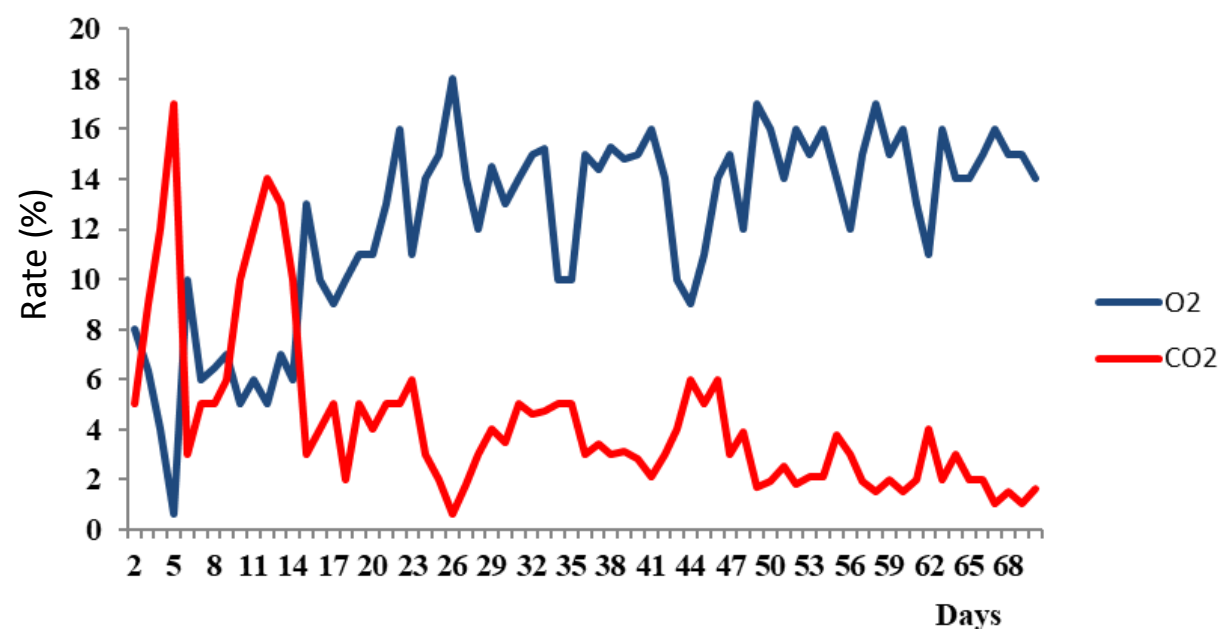

Figure 11. Evolution of $\mathrm{O}_{2}$ and $\mathrm{CO}_{2}$ in the Windrow $\mathrm{D}$.

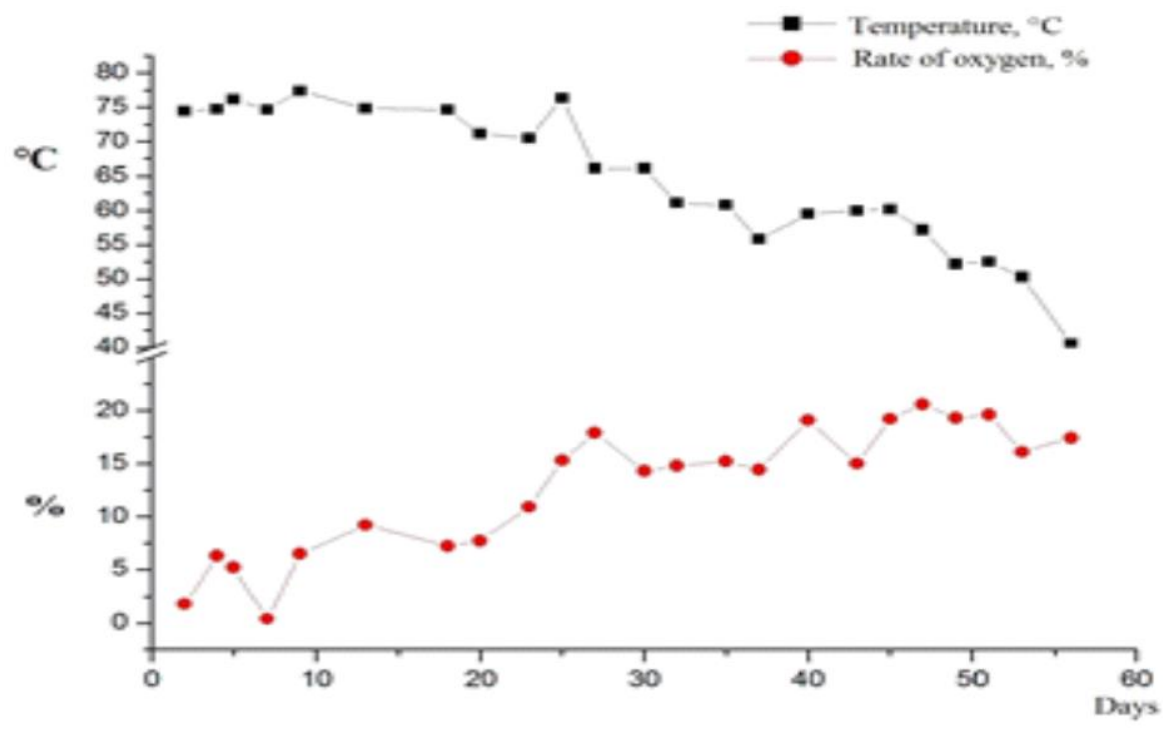

Figure 12. Relationship between $\mathrm{T}^{\circ} \mathrm{C}$ and $\mathrm{O}_{2}$ in the Windrow $\mathrm{D}$.

shows that there is a correlation between temperature, oxygen level and rollovers. In fact, in windrows $A$ and $B$, there is a decrease in temperature over the weeks with accentuated variations just after the turnings (Figure 12). These also act on the oxygen level measured in the windrows which, unlike the temperature, increases over time, tending towards the content of the ambient air and showing the maturity of the compost. In addition, depending on the method of turning, the variations differ; they are more accentuated when the turns are more frequent (windrow $E$ ) than if they are spaced (windrow $A$ ). The decrease in biological activities in the heaps is believed to be the cause of the decrease in temperature and the increase in oxygen content. This is more accentuated when the turns are close together.

\section{Metallic trace element content}

The analysis of TME (Pb, Cd and $\mathrm{Ni}$ ) carried out on the composts gives very low values compared to the threshold values of standard NFU 44-051 (Table 2): less than $60 \mathrm{mg} / \mathrm{kg} \mathrm{DM}$ for $\mathrm{Pb}, \mathrm{Cd}$ is not detected and less than $15 \mathrm{mg} / \mathrm{kg} \mathrm{DM}$ for $\mathrm{Ni}$. These low levels are probably linked to the sorting method which considerably reduces the quantity of fines before windrowing. Since composts are free from TME, they can therefore be used without risk of polluting the soil or the food chain through the 
products that can be obtained after their use.

\section{Conclusion}

The objective of this study is to optimize oxygen consumption and the reduction of organic matter in waste during the fermentation phase. To do this, windrow turning is monitored, which includes monitoring of the consumption of oxygen $\left(\mathrm{O}_{2}\right)$, the production of carbon dioxide $\left(\mathrm{CO}_{2}\right)$, the temperature, the organic matter $(\mathrm{OM})$, humidity, $\mathrm{pH}$ and some metals.

Temperature monitoring shows a gradual decrease until stabilization at room temperature, indicating the maturity of the compost. With a slight increase in all swaths, the $\mathrm{pH}$ remained alkaline.

The humidity in the windrows is acceptable, thus promoting good aerobic degradation of the composted waste.

The organic matter in these windrows has decreased to values which agree with the reference despite the fact that the turning mode had a strong effect on the degradation of the waste.

The present study highlights the importance and influence of the oxygen content and the production of carbon dioxide on the mineralization of organic matter, especially in the fermentation phase. The oxygen level obtained inside the windrows is above the limit thanks to the new turning method implemented on the platform in Lomé which is less tedious and which guarantees an oxygen level above $8 \%$ throughout the composting process. The decrease in biological activities in the heaps could be the cause of the decrease in temperature and the increase in oxygen content. The oxygen content is necessary for the degradation and mineralization of organic matter but the rate of evolution of organic matter is low when the turning is carried out according to this new scheme, therefore when the oxygen supply is high. We may therefore think that there is an upper limit at which the oxygen level must be maintained to reconcile aerobic decomposition and rapid mineralization. It will be interesting in future investigations to seek the maximum oxygen level that can allow aerobic decomposition and rapid mineralization.

The content of metallic trace elements has also been researched and gives composts that are non-toxic and can be used in cultivable areas.

\section{CONFLICT OF INTERESTS}

The authors have not declared any conflict of interests.

\section{ACKNOWLEDGEMENT}

This work received financial support from the French
Funds for the World Environment (FFEM)/UICN, of the Suez Funds, of the French Agency of Development (AFD) and of La Region lles de France. The author appreciate the Head of the Laboratory of Waste Management,Treatment and Recovery (GTVD) in which this work was carried out.

\section{REFERENCES}

Aziablé E, Tchegueni S, Bodjona MB, Degbe AK, Zamama M, Hafidi M, EL Meray M, Kili KA ( 2017). Valorization of agro-industrial waste by bio-process aerobic "composting". Journal of Materials and Environmental Sciences 8(4):1277-1283.

Belyaeva ON, Haynes R (2009). Chemical, microbial and physical properties of manufactured soils produced by co-composting municipal green waste with coal fly ash. BioresourceTechnology 100(21):5203-5209.

Bokobana A, Toundou O, Kolani L, Amouzouvi KAA, Koledzi E, Tozo K, Tchangbedji G (2017). Treatment of household waste by cocomposting with the legume Cassia occidentalis $L$. and some local adjuvants to improve the agronomic quality of composts. Waste Science and Technology-N $\mathrm{N}$ 73-May 2017. https://doi.org/10.4267/dechets-sciences-techniques.3551.

Damien (2004). «Waste management guide, 3rd edition » (Vol. 431). Paris, France. ISBN: 978-2-10-074719-1.www.dunod.com

Koledzi KE (2011). Valorization of solid urban waste in the districts of Lomé (Togo): methodological approach for a sustainable production of compost. Unique PhD thesis, University of Limoges $\mathrm{N}^{\circ}$ 04-2011. P 118.

https://scirp.org/reference/referencespapers. aspx?referenceid=29286 23

Koledzi KE, Aziablé E, Megnassan S (2019). Comparative study of the evolution of mass balance on the ENPRO composting platform in Togo. Journal of Chemical, Biological and Physical Sciences Section D 1(9):127-137.

Krou NM, Baba G, Martin-Pascual J, Zamorano TM (2019). Stabilisation co-composting dry drain sludge with fermentescible fractions of household garbage from the city of Sokodé (Togo). International Journal of Biological and Chemical Sciences 13(7):3234-3246.

Mustin M (1987). Compost: management of organic matter. ED. François Dubusc, Paris $954 \mathrm{p}$.

Puyuelo B, Gea T, Sanchez A (2010). A new control strategy for the composting process based on the oxygen uptake rate. Chemical Engineering Journal 165(1):161-169.

Sánchez A, Artola A, Font X, Gea T, Barrena R, Gabriel D, Ángel M, Sánchez-Monedero, Roig A, Cayuela ML, Mondini C (2015). Greenhouse gas emissions from organic waste composting. Environmental Chemistry Letters 13(3):223-238.

Sundberg C, Smars S, Jonsson $\mathrm{H}$ (2004). Low pH as an inhibiting factor from mesophilic to thermophilic phase in composting. Bioresource Technology (95):145-450.

Tang JC, Kanamori T, Inoue Y, Yasuta T, Yoshida S, Katayama A (2004). Changes in the microbial community structure during thermophilic composting of manure as detected by the quinone profile method. Process Biochemistry (39):1999-2006.

Tchegueni S, Kili AK, Bodjona M, Koriko M, Hafidi M, Baba G, Tchangbedji G (2012). Effects of composts based on citrus waste and shea cake on the availability of soil phosphorus: a study under conditions controlled. International Journal of Biological and Chemical Sciences 6(3):1381-1389.

Tchanaté KN, Segbeaya KN, Koledzi KE, Baba G (2017). Evaluation of the physicochemical and agronomic quality of the composts of urban waste of the towns of lome and Kara in Togo. European Journal of Scientific Research 147(4):469-474.

Toundou (2018). Evaluation of the chemical and agronomic characteristics of five waste composts and study of their effects on the chemical properties of the soil, the physiology and the yield of corn (Zea mays L. Var. Ikenne) and tomato (Lycopersicum esculentum $\mathrm{L}$. Var. Tropimech) under two water regimes in Togo. 
Unique doctoral thesis from the University of Lomé in joint supervision with the University of Limoges. PhD thesis: Applied Plant Biology; Specialty: Plant Physiology P 214.

Turan NG, Ergun NO (2008). The effets of aération modifications on municipal solid waste composting. Fresenius Environmental Bulletin 17(7A):778-785.
Rafolisy T, Thuriès L, Técher P, Moussard G, Paillat JM (2015). « Cocomposting of beer sludge and livestock manure in Réunion: hygienization, loss of nutrients and homogeneity of the compost produced. Biotechnology, Agronomy, Society and Environment 19(4):329-337. 